\title{
Demand shifts and market structure in free-entry oligopoly equilibria
}

\author{
Stephen F. Hamilton \\ Department of Agricultural Economics, Kansas State University, 331B Waters Hall, Manhattan, \\ KS 66506-4011, USA
}

\begin{abstract}
This papers examines the structural implications of demand shifts in free-entry oligopoly equilibria. The model generalizes the conjectural variations framework to consider asymmetric firm conjectures, allows for the possibility of cost differences across firms, and endogenizes conditions of entry and exit in the industry. In non-competitive environments, changes in incumbent output and industry profitability are inversely-related to changes in the equilibrium price following a demand shift. In response to rotations of demand through the equilibrium point, changes in profitability are positively-related to changes in industry concentration and, when marginal costs are non-decreasing, inversely-related to changes in market power.
\end{abstract}

Keywords: Oligopoly; Market power; Industry concentration

\section{Introduction}

The effect of demand shifts on oligopoly market structure has been examined recently by Quirmbach (1988) for the case of a fixed number of homogeneous firms. This paper extends the analysis of demand shifts to a free-entry oligopoly 
equilibrium and finds that entry considerations have a nontrivial affect on industry outcomes. In response to a demand shift, Quirmbach finds that a decline in the equilibrium price is a necessary condition for a decline in industry profitability. We derive the opposite implication for the free-entry case. In non-competitive environments with free-entry, a decline in the equilibrium price following a demand shift is both a necessary and a sufficient condition for increased industry profitability.

The paper highlights an important and heretofore unrecognized connection between the underlying motivation for de novo entry and the structural implications of a demand shift. Specifically, we identify two types of demand shifts which induce entry in an oligopolistic equilibrium: parallel upwards shifts in demand and clockwise rotations of demand through the equilibrium point. The effect of entry on market performance differs markedly between these cases. For a parallel upwards shift in demand, we find that industry output always expands when entry occurs, as in Seade (1980). However, in response to a clockwise rotation of demand through the equilibrium point, industry output always contracts when entry occurs.

Demand shifts in free-entry equilibria also have implications for changes in industry concentration, profitability and market power. In response to demand shifts, we find that changes in industry profitability are positively-related to changes in incumbent output, and, when marginal costs are non-decreasing, inversely-related to changes in incumbent price-cost margins. In a wide range of circumstances, increased profitability is also associated with a decline in the equilibrium number of firms, whence increased profitability tends to occur with heightened industry concentration, as in Clarke and Davies (1982); Dansby and Willig (1979), and Dixit and Stern (1982).

Most theoretical analyses suggest that concentration is positively-related to price-cost margins in an industry (e.g., Cowling and Waterson, 1976 and Harris, 1988). Somewhat paradoxically, however, intra-industry studies often find quite the opposite. For example, Schroeter (1988); Koontz et al. (1993); Murray (1995), and Nebesky et al. (1995) all report decreasing market power estimates during periods of heightened industry concentration. In a free-entry oligopoly equilibrium, we show that industry concentration tends to vary inversely with incumbent price-cost margins in response to a demand shift. Indeed, we find that the very circumstances which allow market power to be identified in intra-industry studies always lead to antithetical changes in concentration and market power.

The paper considers a conjectural variations equilibrium which allows for cost differences across firms. In this regard, the model is contextually similar to the asymmetric-cost oligopoly models of Dierickx et al. (1988); Hamilton and Sandin (1997), and Kimmel (1992) for demand shifts which arise through industry taxation. We show that downward shifts in industry demand may increase the profits of low-cost firms, which extends the result of Dierickx et al. (1988) and Kimmel (1992) to a free-entry oligopoly equilibrium. The demand shift approach to taxation also allows analytically convenient analysis of comparative incidence. 
As in Dierickx et al. (1988), we find that increases in low-cost market share are more likely to occur in response to downward shifts in demand which are combined with counterclockwise rotations (e.g., ad valorem taxation) than with parallel downward shifts (e.g. unit taxation). Moreover, a revenue neutral tax reform from specific to ad valorem taxation increases both industry output and profitability, whence ad valorem taxes Pareto-dominate specific taxes in the sense of Skeath and Trandel (1994).

To capture a wide range of oligopoly outcomes, the conjectural variations approach is generalized to consider cases in which conjectures differ across firms. Thus, the framework nests all familiar forms of quantity competition, including the case of dominant firm(s) with a competitive fringe, in a single model. The qualitative implications of the model are robust to alternative conjectures and hold in the Cournot-Nash case as well as for less theoretically-supported conjectures.

The remainder of the paper is structured as follows. In section 2, a model of free-entry oligopoly is developed which considers asymmetric firm conjectures, allows for differences in the productive efficiency of firms, and endogenizes conditions of entry and exit. Section 3 presents comparative statics effects of a demand shift on the output of incumbent firms and on the equilibrium number of firms. Several propositions are derived regarding the effect of a demand shift on industry output, the equilibrium price, incumbent market shares, market power, industry concentration and profitability. Concluding comments are provided in section 4.

\section{A generalized model of free-entry oligopoly}

The foundation for the following analysis is a conjectural variations oligopoly model with endogenous entry as conceived by Seade (1980) and employed by Besley (1989), Delipalla and Keen (1992), and Mankiw and Whinston (1986). The model distinguishes between small, high-cost firms and large, relatively cost-efficient firms as in Dierickx et al. (1988); Hamilton and Sandin (1997), and Kimmel (1992). ${ }^{1}$ Conjectures are allowed to differ in the model between low- and high-cost firms, which extends the conjectural variations approach to encompass other familiar forms of quantity competition such as the case of dominant firm(s) with a competitive fringe.

Consider an equilibrium comprised of $N=n_{1}+n_{\mathrm{h}}$ firms which produce a

\footnotetext{
${ }^{1}$ One might expect the cost structure of firms in an industry to differ due to varying rates of success in the innovation game. Cost differences may persist in equilibrium when patents and rival priceresponse behavior preempt imitation by high-cost firms (see Harris, 1988; Reinganum, 1985 and Vickers, 1986).

${ }^{2}$ Equilibrium behavior is modeled here in the context of a simultaneous move game. Extension of the model to a sequential move game would be relatively straightforward.
} 
homogeneous good, where $n_{l}$ is the number of low-cost firms, each with the cost function $c_{1}\left(y_{1}\right)$, and $n_{\mathrm{h}}$ is the number of high-cost firms, each with the cost function $c_{\mathrm{h}}\left(y_{\mathrm{h}}\right)$. The output of a low- and high-cost representative firm is denoted $y_{1}$ and $y_{\mathrm{h}}$, respectively. The profit of firm $i$ is

$$
\pi^{i}=P(Y) y_{i}-c_{i}\left(y_{i}\right)
$$

where $Y=\sum_{i} y_{i}$ is total industry output and $P(Y)$ is the inverse demand function.

The relative efficiency of a representative firm in each sub-group is described as follows: Firm 1 is (weakly) more efficient than firm $\mathrm{h}$ whenever

$$
\left.\frac{\mathrm{d} c_{1}\left(y_{1}\right)}{\mathrm{d} y_{1}}\right|_{y_{i} *} \leqslant\left.\frac{\mathrm{d} c_{\mathrm{h}}\left(y_{\mathrm{h}}\right)}{\mathrm{d} y_{\mathrm{h}}}\right|_{y_{\mathrm{h}}{ }^{*}}
$$

Condition (2) states that the marginal cost of a low-cost producer is no greater than that of a high-cost producer at the respective equilibrium output levels. To achieve greater clarity in the comparative statics results, we further define the relative efficiency of low- and high-cost firms with respect to marginal perturbations in output. Specifically, we wish to eliminate the somewhat unusual case in which a small, high-cost firm has higher marginal cost than a large, low-cost firm, but has greater capacity to expand production in response to a demand shift. To maintain the identity of high- and low-cost firms for a marginal expansion in output, we impose

$$
\left.\frac{\mathrm{d}^{2} c_{1}\left(y_{1}\right)}{\mathrm{d}\left(y_{1}\right)^{2}}\right|_{y_{1} *} \leqslant\left.\frac{\mathrm{d}^{2} c_{\mathrm{h}}\left(y_{\mathrm{h}}\right)}{\mathrm{d}\left(y_{\mathrm{h}}\right)^{2}}\right|_{y_{\mathrm{h}} *} .
$$

Condition (3) states that a marginal expansion of output does not raise the marginal cost function of a low-cost firm by more than that of a high-cost firm. This condition eliminates ambiguity in the definition of low-cost firms by ruling out situations in which high- and low-cost firms switch identity in response to small perturbations of output. ${ }^{3}$

Differentiating profit expression (1), the first-order condition for firm $i$ is

$$
\pi_{y_{i}}^{i}=P+\delta_{i} P^{\prime} y_{i}-c_{y_{i}}^{i}=0,
$$

where $P^{\prime}<0$ denotes the derivative of inverse demand with respect to industry output. The second-order condition of firm $i$ is

\footnotetext{
${ }^{3}$ Condition (3) is sufficient, though not necessary, for the results that follow. Such a condition is likely to be met in practical applications, as low-cost firms may have higher marginal costs at low levels of output, yet be operating at a scale which is well beyond any crossing of marginal cost with high-cost firms.

${ }^{4}$ For notational convenience, the arguments of the demand function are hereafter suppressed.
} 


$$
\pi_{y_{i} y_{i}}^{i}=2 \delta_{i} P^{\prime}+\delta_{i}^{2} P^{\prime \prime} y_{i}-c_{y_{i} y_{i}}^{i}<0,
$$

where $\delta_{i}=\partial Y / \partial y_{i}$ is the conjectural variations parameter. Throughout, we consider symmetric conjectures within each subgroup, though the conjecture of a low-cost firm may differ from that of a high-cost firm. When conjectures are symmetric across all firms in an industry, the model reduces to familiar cases of perfectly competitive behavior $\left(\delta_{i}=0, \forall_{i}\right)$, Cournot-Nash behavior $\left(\delta_{i}=1, \forall_{i}\right)$, and tacit collusion $\left(\delta_{i}=n_{i}, \forall_{i}\right)$. When conjectures differ across firms, the model reduces to the special case of low-cost dominant firm(s) with a high-cost competitive fringe with restrictions $\delta_{\mathrm{h}}=0$ and $\delta_{1}=n_{1}$. The model generalizes other potential market structures as well, such as the case of Cournot-Nash behavior by low-cost firms with a competitive fringe or Cournot-Nash behavior by high-cost firms with a low-cost producer cartel.

Confining attention to symmetric subgroup equilibria, the first-order condition (4) is expressed in terms of an average firm within each subgroup as

$$
\pi_{y_{i}}^{i}=P+\gamma_{i} Y_{i} P^{\prime}-c_{y_{i}}^{i}=0,
$$

where $\gamma_{i}=\delta_{i} / n_{i} \in[0,1]$ and $Y_{i}=n_{i} y_{i}$ represents the total output of firms in subgroup $i$.

To address entry in the model, the number of high-cost firms is treated as a continuous variable following Besley (1989), Mankiw and Whinston (1986), and Seade (1980). Demand shifts are assumed to be modest enough to not affect the number of low-cost firms, whence attention is confined to small firm entry and exit. ${ }^{5}$ Low-cost firms receive positive profits in equilibrium, while the entry of small, relatively-inefficient firms occurs until profit is driven to zero in the high-cost industry subgroup. In equilibrium, the number of high-cost firms in the industry, $n_{\mathrm{h}}^{*}$, solves

$$
\pi^{\mathrm{h} *}=P\left(Y^{*}\right) y_{\mathrm{h}}^{*}-c_{\mathrm{h}}\left(y_{\mathrm{h}}^{*}\right)=0,
$$

where $Y^{*}=n_{1} y_{1}^{*}+n_{\mathrm{h}}^{*} y_{\mathrm{h}}^{*}$. The equilibrium number of high-cost firms is determined simultaneously with $y_{1}^{*}$ and $y_{\mathrm{h}}^{*}$ from the first-order conditions (6) and the entry condition (7). ${ }^{6}$

The conditions for existence and stability are analogous to those of Dixit (1986) and Seade (1987):

$$
k_{i}>0,
$$

\footnotetext{
${ }^{5}$ That small scale, de novo entry appears to be more common than the entry of large firms in most industries is supported by Geroski (1995).

${ }^{6}$ It is assumed throughout that the equilibrium number of high-cost firms is unique, as is the case when at least a portion of fixed costs are sunk (Vickers, 1989).
} 
where $k_{i}=c_{y_{i} y_{i}}^{i}-\delta_{i} \mathrm{P}^{\prime}$, and

$$
P^{\prime}+P^{\prime \prime} Y \leqslant 0 \text {. }
$$

In addition, we confine attention to cases in which the conjecture of a representative low-cost firm is no less than that of a high-cost firm,

$$
\delta_{1} \geqslant \delta_{\mathrm{h}}
$$

Expression (10) allows for the possibility that small, high-cost firms may feel more able to get away with output changes undetected than larger firms.

Lemma 1. The asymmetric-cost equilibrium satisfies $\delta_{1} y_{1} \geqslant \delta_{\mathrm{h}} y_{\mathrm{h}}$.

Proof. Equating first-order condition (4) for a representative low- and high-cost firm, $P^{\prime}\left(\delta_{1} y_{1}-\delta_{h} y_{h}\right)=c_{1}^{\prime}-c_{h}^{\prime}$. The proof follows directly from marginal cost condition (2).

Lemma 2. $Y-\delta_{\mathrm{h}} y_{\mathrm{h}}>0$.

Proof. Industry output may be decomposed into subgroup output as $Y=Y_{\mathrm{h}}+Y_{1}$, whence $Y-\delta_{\mathrm{h}} y_{\mathrm{h}}=Y_{1}+\left(1-\gamma_{\mathrm{h}}\right) Y_{\mathrm{h}}$, which is positive by $\gamma_{\mathrm{h}} \leqslant 1$.

\section{Demand shifts and industry equilibrium}

Following Dixit (1986) and Quirmbach (1988), let $\theta$ represent a demand-side interaction variable; that is, $P=P(Y ; \theta)$. A movement in the interaction variable may induce a vertical shift in demand, a rotation of demand through the initial equilibrium point, or some combination of the two effects.

The comparative statics effects of a demand shift are calculated by totally differentiating the first-order condition (6) for a representative firm in each sub-group and entry condition (7), making use the envelope theorem. Combining equations, we have

$$
\left[\begin{array}{ccc}
\lambda_{1} & n_{\mathrm{h}} \omega_{1} & y_{\mathrm{h}} \omega_{1} \\
n_{1} \omega_{\mathrm{h}} & \lambda_{\mathrm{h}} & y_{\mathrm{h}} \omega_{\mathrm{h}} \\
n_{1} P^{\prime} y_{\mathrm{h}} & \left(1-\gamma_{\mathrm{h}}\right) P^{\prime} Y_{\mathrm{h}} & P^{\prime}\left(y_{\mathrm{h}}\right)^{2}
\end{array}\right]\left[\begin{array}{c}
\mathrm{d} y_{1} \\
\mathrm{~d} y_{\mathrm{h}} \\
\mathrm{d} n_{\mathrm{h}}
\end{array}\right]=-\left[\begin{array}{c}
P_{\theta}+\gamma_{1} Y_{1} P_{\theta}^{\prime} \\
P_{\theta}+\gamma_{\mathrm{h}} Y_{\mathrm{h}} P_{\theta}^{\prime} \\
P_{\theta} y_{\mathrm{h}}
\end{array}\right] \mathrm{d} \theta,
$$

where $\omega_{i}=\left(P^{\prime}+\gamma_{i} Y_{i} P^{\prime \prime}\right)$ and $\lambda_{i}=\pi_{y_{i} y_{i}}^{i}+n_{i}\left(1-\gamma_{i}\right) \omega_{i}$. Denoting the coefficient matrix in (11) by $\boldsymbol{\Omega}$, its determinant is

$$
\operatorname{Det}(\Omega)=-y_{\mathrm{h}}^{2} P^{\prime} k_{1} \pi_{y_{\mathrm{h}} y_{\mathrm{h}}}^{\mathrm{h}},
$$

which is negative by the second-order condition (5) with the stability condition (8). 
The effects of a demand shift on the output of a high- and low-cost firm are

$$
\frac{\mathrm{d} y_{\mathrm{h}}}{\mathrm{d} \theta}=\frac{\delta_{\mathrm{h}} y_{\mathrm{h}} \Phi}{P^{\prime} \pi_{y_{\mathrm{h}} y_{\mathrm{h}}}^{\mathrm{h}}},
$$

and

$$
\frac{\mathrm{d} y_{1}}{\mathrm{~d} \theta}=\frac{\left[\delta_{1} y_{1} k_{\mathrm{h}}-\delta_{\mathrm{h}} P^{\prime}\left(\delta_{1} y_{1}-\delta_{\mathrm{h}} y_{\mathrm{h}}\right)\right] \Phi}{P^{\prime} k_{1} \pi_{y_{\mathrm{h}} y_{\mathrm{h}}}^{\mathrm{h}}},
$$

respectively, where $\Phi=\left(P_{\theta} P^{\prime \prime}-P_{\theta}^{\prime} P^{\prime}\right)$. For demand shifts which satisfy $P_{\theta}=0, \Phi$ may be written in elasticity form as, $\Phi=\left(\varepsilon_{P^{\prime}, Y}-\varepsilon_{P_{\theta}, Y}\right) P_{\theta} P^{\prime} / Y$, where $\epsilon_{P^{\prime}, Y}=P^{\prime \prime} Y /$ $P^{\prime}$ is the elasticity of the slope of inverse demand and $\epsilon_{P_{\theta}, Y}=P_{\theta}^{\prime} Y / P_{\theta}$ is the price elasticity of the shift in demand. If one thinks of demand as a surface in $(P, Y, \theta)$, then the term in the parentheses is positive if the slope of the demand surface in the direction of the output axis is more sensitive to changes in output than is the slope of the demand surface in the direction of the shift parameter.

A change in the interaction variable affects the number of high-cost firms as

$$
\frac{d n_{\mathrm{h}}}{d \theta}=\frac{-\left\{P_{\theta} k_{1} \pi_{y_{\mathrm{h}} y_{\mathrm{h}}}^{\mathrm{h}}+\Phi\left[\delta_{1} Y_{\mathrm{l}} k_{\mathrm{h}}+\delta_{\mathrm{h}} Y_{\mathrm{h}} k_{\mathrm{l}}\left(1-\gamma_{\mathrm{h}}\right)-n_{1} \delta_{\mathrm{h}} P^{\prime}\left(\delta_{1} y_{1}-\delta_{\mathrm{h}} y_{\mathrm{h}}\right)\right]\right\}}{P^{\prime} y_{\mathrm{h}} k_{1} \pi_{y_{\mathrm{h}} y_{\mathrm{h}}}^{\mathrm{h}}} .
$$

The signs of expressions (12), (13), and (14) depend on industry conjectures, the level effect $\left(P_{\theta}\right)$ and rotation effect $\left(\mathrm{P}_{\theta}^{\prime}\right)$ of the shift. When a demand shift involves an upwards level effect $\left(P_{\theta}>0\right)$, the first term in the numerator of (14) reflects the entry incentive created by an increase in the marginal profitability of high-cost firms. In noncompetitive environments, a shift in demand also creates a strategic entry effect through $\Phi$. The strategic effect depends on both the rotation effect and the concavity of demand. If demand is concave, incumbent firms operate in a region where marginal revenue is fairly steep and thus make smaller output adjustments to restore their first-order conditions relative to the case of linear demand. In response to a demand shift, the greater the concavity of demand, the smaller the output response of incumbent firms and the larger the latitude for high-cost firm entry.

The ultimate effect of a demand shift depends on the specific combination of level and rotation effects which occur in the industry equilibrium. Throughout, we refer to the rotation effect as one of clockwise rotation $\left(P_{\theta}^{\prime}<0\right)$ or counterclockwise rotation $\left(P_{\theta}^{\prime}>0\right)$ and center attention on the separate effects of parallel shifts and demand rotations. Demand shifts, in general, affect industry structure through different aggregations of these outcomes. 
Proposition 1. The following effects occur in response to a counterclockwise (resp. clockwise) rotation of demand through the equilibrium point:

1. the number of high-cost firms does not change when $\delta_{i}=0, \forall i$; when $\delta_{1}>0$, high-cost exit (resp. entry) occurs;

2. industry output does not change when $\delta_{\mathrm{h}}=0 ;$ when $\delta_{\mathrm{h}}>0$, industry output increases (resp. decreases);

3. the market share of firm $i$ does not change when $\delta_{i}=0$; when $\delta_{i}>0$ the market share of firm i increases (resp. decreases);

4. the $\mathrm{CR}(k)$ index of industry concentration does not change when $\delta_{i}=0, \forall i$; when $\delta_{1}>0$, the $\mathrm{CR}(k)$ increases (resp. decreases);

5. If the marginal cost of a representative high-cost firm in non-decreasing in output, the elasticity of demand increases (resp. decreases).

Proof. We first consider the case of counterclockwise rotation $\left(P_{\theta}=0\right.$ and $\left.P_{\theta}^{\prime}>0\right)$. When $\delta_{i}=0, \forall \mathrm{i}$, the number of firms remains constant in (14). When $\delta_{i}>0$, the numerator of (14) is negative by (8) and lemma 1 . The denominator of (14) is positive by (5) and (8). It follows that exit of high-cost firms occurs in response to counterclockwise rotations of demand. The opposite is true for $P_{\theta}=0$ and $P_{\theta}^{\prime}<0$.

The change in industry quantity is calculated from (12), (13), and (14) as $\mathrm{d} Y / \mathrm{d} \theta=n_{1}\left(\mathrm{~d} y_{1} / \mathrm{d} \theta\right)+n_{\mathrm{h}}\left(\mathrm{d} y_{\mathrm{h}} / \mathrm{d} \theta\right)+y_{\mathrm{h}}\left(d n_{\mathrm{h}} / \mathrm{d} \theta\right)$, which yields

$$
\frac{d Y}{d \theta}=\frac{-P_{\theta} \pi_{y_{\mathrm{h}} y_{\mathrm{h}}}^{h}+\Phi \delta_{\mathrm{h}}^{2} y_{\mathrm{h}}}{P^{\prime} \pi_{y_{\mathrm{h}} y_{\mathrm{h}}}^{h}} .
$$

The denominator of (15) is positive by (5). For $P_{\theta}=0$ and $P_{\theta}^{\prime}>0$, a demand shift has no effect on industry output when $\delta_{\mathrm{h}}>0$. When $\delta_{\mathrm{h}}>0$, the numerator of (15) is positive, whence industry output increases. The opposite is true for $P_{\theta}=0$ and $P_{\theta}^{\prime}<0$, which completes part (ii).

The market share of firm $i$ is given by $s_{i}=y_{i} / Y$, whence the effect on market share is $\mathrm{d} s_{i} / \mathrm{d} \theta=Y^{-2}\left[Y\left(\mathrm{~d} y_{i} / \mathrm{d} \theta\right)-y_{i}(\mathrm{~d} Y / \mathrm{d} \theta)\right]$. Using (12), (13), and (15), a demand shift affects the market share of a representative high- and low-cost firm as

$$
\frac{\mathrm{d} s_{\mathrm{h}}}{\mathrm{d} \theta}=\frac{y_{\mathrm{h}}\left[P_{\theta} \pi_{y_{\mathrm{h}} y_{\mathrm{h}}}^{\mathrm{h}}+\Phi \delta_{\mathrm{h}}\left(Y-\delta_{\mathrm{h}} y_{\mathrm{h}}\right)\right]}{P^{\prime} Y^{2} \pi_{y_{\mathrm{h}} y_{\mathrm{h}}}^{h}}
$$

and

$$
\frac{\mathrm{d} s_{1}}{\mathrm{~d} \theta}=\frac{P_{\theta} y_{1} k_{1} \pi_{y_{\mathrm{h}} y_{\mathrm{h}}}^{h}+\Phi\left[y_{1}\left(\delta_{1} Y k_{\mathrm{h}}-\delta_{\mathrm{h}}^{2} y_{\mathrm{h}} k_{1}\right)-\delta_{\mathrm{h}} P^{\prime} Y\left(\delta_{1} y_{1}-\delta_{\mathrm{h}} y_{\mathrm{h}}\right)\right]}{P^{\prime} Y^{2} k_{1} \pi_{y_{\mathrm{h}} y_{\mathrm{h}}}^{h}},
$$

respectively. The denominator of (16) is positive by (5), while the denominator of 
(17) is positive by (5) and (8). For the case of counterclockwise rotation, high-cost market share does not change in (16) when $\delta_{\mathrm{h}}=0$. When $\delta_{1}=0, \delta_{\mathrm{h}}=0$ by condition (10), which implies low-cost market share does not change in (17). When $\delta_{\mathrm{h}}>0$, the numerator of (16) is positive by lemma 2, whence high-cost market share increases. When $\delta_{1}>0$, a sufficient condition for low-cost market share to increase in (17) is $\left(\delta_{1} Y k_{\mathrm{h}}-\delta_{\mathrm{h}}^{2} y_{\mathrm{h}} k_{1}\right)>0$ by lemma 1 . Adding and subtracting $\delta_{\mathrm{h}} k_{l} Y$ to this term gives, $\left(\delta_{1} Y k_{\mathrm{h}}-\delta_{\mathrm{h}}^{2} y_{\mathrm{h}} k_{1}\right)=Y\left(\delta_{1} c_{y_{\mathrm{h}} y_{\mathrm{h}}}^{\mathrm{h}}-\delta_{\mathrm{h}} c_{y_{1} y_{1}}^{1}\right)+\delta_{\mathrm{h}} k_{1}\left(Y-\delta_{\mathrm{h}} y_{\mathrm{h}}\right)$, where the first term is positive by (3) and (10) and the second term is positive by lemma 2 . The opposite is true for $P_{\theta}=0$ and $P_{\theta}^{\prime}<0$.

The change in the $\operatorname{CR}(k)$ is, $k\left(\mathrm{~d} s_{1} / \mathrm{d} \theta\right), \forall k \leqslant n_{1}$, whence the $\operatorname{CR}(k)$ index does not change when $\delta_{1}=0$, but increases for $P_{\theta}=0$ and $P_{\theta}^{\prime}>0$ when $\delta_{1}>0$ as a corollary to part (iii). If $k>n_{1}$, the $\mathrm{CR}(k)$ index sums the market share of firms in the low-cost subgroup plus a fraction of firms in the high-cost subgroup, which implies $\mathrm{d}[\mathrm{CR}(k)] / \mathrm{d} \theta=n_{1}\left(\mathrm{~d} s_{1} / \mathrm{d} \theta\right)+\left(k-n_{1}\right)\left(\mathrm{d} s_{\mathrm{h}} / \mathrm{d} \theta\right)$. This expression reduces to $n_{1}\left(\mathrm{~d} s_{1} / \mathrm{d} \theta\right)$ when $\delta_{\mathrm{h}}=0$ in $(16)$. When $\delta_{\mathrm{h}}>0$, the change in the $\mathrm{CR}(k)$ index is positive as market share increases for a firm in either subgroup. The opposite is true for $P_{\theta}=0$ and $P_{\theta}^{\prime}<0$.

Denoting the absolute value of the demand elasticity as $\eta=-P / P^{\prime} Y$, the effect of a demand shift on the demand elasticity is calculated from (15) as

$$
\frac{\mathrm{d} \eta}{\mathrm{d} \theta}=\left(P^{\prime} Y\right)^{-2}\left\{P P^{\prime}\left(\frac{\mathrm{d} Y}{\mathrm{~d} \theta}\right)+P Y\left(P_{\theta}^{\prime}+P^{\prime \prime}\left(\frac{\mathrm{d} Y}{\mathrm{~d} \theta}\right)\right)-P^{\prime} Y\left(P_{\theta}+P^{\prime}\left(\frac{\mathrm{d} Y}{\mathrm{~d} \theta}\right)\right)\right\},
$$

which yields,

$$
\frac{\partial \eta}{\partial \theta}=\frac{-P P^{\prime} P_{\theta} \pi_{y_{\mathrm{h}} y_{\mathrm{h}}}^{\mathrm{h}}+\Phi\left[P Y k_{\mathrm{h}}-\delta_{\mathrm{h}} P^{\prime} Y\left(P+\delta_{\mathrm{h}} y_{\mathrm{h}} P^{\prime}\right)+\delta_{\mathrm{h}}^{2} y_{\mathrm{h}} P P^{\prime}\right]}{\left(P^{\prime} Y\right)^{2} P^{\prime} \pi_{y_{\mathrm{h}} y_{\mathrm{h}}}^{\mathrm{h}}} .
$$

The denominator of (18) is positive, while the numerator is of ambiguous sign. For $P_{\theta}=0$ and $P_{\theta}^{\prime}>0$, the numerator is positive when $P Y k_{\mathrm{h}}+\delta_{\mathrm{h}}^{2} y_{\mathrm{h}} P P^{\prime}>0$ by firstorder condition (4). Factoring this expression, $P Y k_{\mathrm{h}}+\delta_{\mathrm{h}}^{2} y_{\mathrm{h}} P P^{\prime}=P\left[Y c_{y_{\mathrm{h}} y_{\mathrm{h}}}^{\mathrm{h}}-\right.$ $\left.\delta_{\mathrm{h}} P^{\prime}\left(Y-\delta_{\mathrm{h}} y_{\mathrm{h}}\right)\right]$, whence $c_{y_{\mathrm{h}} y_{\mathrm{h}}}^{h} \geqslant 0$ is a sufficient condition for $\partial \eta / \partial \theta>0$ by lemma 2. The opposite result obtains for $P_{\theta}=0$ and $P_{\theta}^{\prime}<0$. Q.E.D.

Proposition 2. The following effects occur in response to a parallel upwards (resp. downwards) shift in demand:

1. industry output increases (resp decreases);

2. entry (resp. exit) occurs if the marginal cost function of a representative low-cost firm is non-decreasing in output;

3. high-cost market share decreases (resp. increases); low-cost market share decreases (resp. increases) if the marginal cost function of a representative low-cost firm is non-decreasing in output;

4. the $C R(k)$ index of industry concentration decreases (resp. increases) if the 
marginal cost function of a representative low-cost firm is non-decreasing in output;

5. the elasticity of demand decreases (resp. increases) if the marginal cost function of a representative high-cost firm is non-decreasing in output.

Proof. A parallel shift in demand affects industry output in expression (15) as

$$
\frac{\mathrm{d} Y}{\mathrm{~d} \theta}=\frac{P_{\theta}\left[k_{\mathrm{h}}-\delta_{\mathrm{h}} P^{\prime}\right]}{P^{\prime} \pi_{y_{\mathrm{h}} y_{\mathrm{h}}}^{\mathrm{h}}},
$$

which is positive for $P_{\theta}>0$ by (5) and (8). The opposite is true for $P_{\theta}<0$.

For a parallel outward shift in demand, entry of high-cost firms occurs in expression (14) whenever $P^{\prime \prime} \leqslant 0$ by (8) and lemma 1 , as $\Phi>0$. The remaining case is that of convex demand. If $P_{\theta}^{\prime}=0$, the number of high-cost firms changes as

$$
\frac{\mathrm{d} n_{\mathrm{h}}}{\mathrm{d} \theta}=\frac{P_{\theta}\left[c_{y_{1} y_{1}}^{1} k_{\mathrm{h}}-\delta_{1} k_{\mathrm{h}}\left(P^{\prime}+P^{\prime \prime} Y_{1}\right)-\delta_{\mathrm{h}} k_{1}\left(P^{\prime}+P^{\prime \prime} Y_{\mathrm{h}}\right)-\delta_{\mathrm{h}} P^{\prime}\left(\delta_{\mathrm{h}} y_{\mathrm{h}} n_{1} P^{\prime \prime}-\delta_{1}\left(P^{\prime}+P^{\prime \prime} Y\right)\right)\right]}{P^{\prime} y_{\mathrm{h}} k_{1} \pi_{y_{\mathrm{h}} y_{\mathrm{h}}}^{\mathrm{h}}} .
$$

The denominator of (20) is positive by (5) and (8). For $P_{\theta}>0$, the numerator is positive when $P^{\prime \prime}>0$ if the marginal cost function of a representative low-cost firm is non-decreasing by conditions (8) and (9), whence entry occurs following a parallel outward shift in demand. The opposite is true for $P_{\theta}<0$.

A parallel outward shift in demand decreases the market share of each incumbent firm when $P^{\prime \prime} \leqslant 0$, as the numerator of (16) is negative by lemma 2 and the numerator of (17) is negative by (3), (10), and the lemmas. A parallel shift affects market shares as

$$
\frac{\mathrm{d} s_{\mathrm{h}}}{\mathrm{d} \theta}=\frac{-P_{\theta}\left[k_{\mathrm{h}}-\delta_{\mathrm{h}}\left(P^{\prime}+P^{\prime \prime} Y\right)\right]}{P^{\prime} Y^{2} \pi_{y_{\mathrm{h}} y_{\mathrm{h}}}^{\mathrm{h}}}
$$

and

$$
\frac{\mathrm{d} s_{1}}{\mathrm{~d} \theta}=\frac{-P_{\theta}\left[y_{1}\left(k_{\mathrm{h}}-\delta_{\mathrm{h}} P^{\prime}\right)\left(c_{y_{1} y_{1}}^{1}-\delta_{1}\left(P^{\prime}+P^{\prime \prime} Y\right)\right)-\delta_{\mathrm{h}}^{2} y_{\mathrm{h}} P^{\prime} P^{\prime \prime} Y\right]}{P^{\prime} Y^{2} k_{1} \pi_{y_{\mathrm{h}} y_{\mathrm{h}}}^{\mathrm{h}}},
$$

for high- and low-cost firms, respectively. Both denominators are positive, as before. The numerator of (21) is negative for $P_{\theta}>0$ by (8) and (9), while the numerator of (22) is negative if the marginal cost function of a representative low-cost firm is non-decreasing by (8) and (9). It follows that incumbent market shares decrease. The opposite is true for $P_{\theta}<0$, which completes part (iii). Noting the argument in part (iv) of proposition 1, the effect of a parallel shift on the $\mathrm{CR}(k)$ index of industry concentration follows directly.

If the marginal cost function of a representative firm is non-decreasing in output, the elasticity of demand decreases for $P_{\theta}>0$ when $P^{\prime \prime} \leqslant 0$ when by (4) and lemma 2. A parallel shift changes the elasticity of demand as 


$$
\frac{\partial \eta}{\partial \theta}=\frac{-P_{\theta}\left[\delta_{\mathrm{h}}^{2} y_{\mathrm{h}}\left(P^{\prime}\right)^{2} P^{\prime \prime} Y-P\left(k_{\mathrm{h}}-\delta_{\mathrm{h}} P^{\prime}\right)\left(P^{\prime}+P^{\prime \prime} Y\right)\right]}{\left(P^{\prime} Y\right)^{2} P^{\prime} \pi_{y_{\mathrm{h}} y_{\mathrm{h}}}^{\mathrm{h}}},
$$

where the denominator of (23) is positive by (5). If $P^{\prime \prime}>0$ the numerator is negative when $P_{\theta}>0$ by (8) and (9). The opposite is true when $P_{\theta}<0$. Q.E.D.

Propositions 1 and 2 illuminate several interesting observations regarding market structure in free-entry equilibria. For example, our results modify the finding of Seade (1980) that industry output always expands as entry occurs in a free-entry oligopoly equilibrium. If entry is motivated by a parallel upwards shift in demand, proposition 2 reflects the fact that industry output indeed expands as entry occurs when the marginal cost functions of low-cost firms are non-decreasing. However, exactly the opposite result obtains when the stimulus for entry is a clockwise rotation of demand, as industry output always contracts with entry under these circumstances by proposition 1 .

In noncompetitive environments, changes in the equilibrium number of highcost firms are inversely-related to changes in the demand elasticity in propositions 1 and 2. When a demand shift increases the demand elasticity, concentration also tends to increase. A positive relationship between industry concentration and the elasticity of demand has been reported elsewhere in the literature on oligopoly, both theoretically (e.g., Cowling and Waterson, 1976; Clarke and Davies, 1982) and empirically (Pagoulatos and Sorenson, 1986; Joesch and Zick, 1994).

Proposition 3. If $\Phi>0$ (resp. $<0$ );

1. the equilibrium price does not change when $\delta_{\mathrm{h}}=0$; when $\delta_{\mathrm{h}}>0$, the equilibrium price decreases (resp. increases);

2. the output of firm $i$ does not change when $\delta_{i}>0, \forall i$, when $\delta_{i}>0$, the output of firm i increases (resp. decreases);

3. industry profitability does not change when $\delta_{1}=0$; when $\delta_{1}>0$, industry profitability increases (resp. decreases);

4. the price-cost margin of firm $i$ does not change when $\delta_{\mathrm{i}}=0$; when $\delta_{\mathrm{i}}>0$, the price-cost margin of firm $i$ decreases (resp. increases) if the marginal cost function of firm $i$ is non-decreasing in output;

Proof. The change in the equilibrium price, $\mathrm{d} P / \mathrm{d} \theta=P_{\theta}+P^{\prime}(\mathrm{d} Y / \mathrm{d} \theta)$, reduces to

$$
\frac{\mathrm{d} P}{\mathrm{~d} \theta}=\frac{\delta_{\mathrm{h}}^{2} y_{\mathrm{h}} \Phi}{\pi_{y_{\mathrm{h}} y_{\mathrm{h}}}^{\mathrm{h}}},
$$

\footnotetext{
${ }^{7}$ Entry may occur when the elasticity of demand increases, however, for demand shifts which involve both $P_{\theta}>0$ and $P_{\theta}^{\prime}>0$ or both $P_{\theta}<0$ and $P_{\theta}^{\prime}<0$.
} 
where the denominator of (24) is negative by (5). When $\delta_{\mathrm{h}}=0$, a demand shift has no effect on the equilibrium price. When $\delta_{\mathrm{h}}>0$, the numerator of (24) is positive iff $\Phi>0$.

When $\delta_{\mathrm{h}}=0$, the output of a representative high-cost firm does not change in (12). When $\delta_{\mathrm{h}}>0$, the output of a high-cost firm increases iff $\Phi>0$, as the denominator of (12) is positive by second-order condition (5). When $\delta_{1}=0, \delta_{\mathrm{h}}=0$, by condition (10) and the output of a representative low-cost firm does not change. When $\delta_{1}>0$, the output of a low-cost firm increases in (13) iff $\Phi>0$ by (5), (8) and lemma 1 .

Industry profitability, $\Pi$, sums low-cost firm profits in the free-entry oligopoly equilibrium. The change in industry profitability in response to a demand shift is thus $\mathrm{d} \Pi / \mathrm{d} \theta=n_{1}\left[y_{1}(\mathrm{~d} P / \mathrm{d} \theta)+\left(P-c_{y_{1}}^{1}\right)\left(\mathrm{d} y_{1} / \mathrm{d} \theta\right)\right]$. Recognizing that $P^{\prime}-c_{y_{1}}^{1}=-$ $P^{\prime} \delta_{1} y_{1}$ by first-order condition (4), a demand shift affects industry profitability as

$$
\frac{\partial \Pi}{\partial \theta}=\frac{-n_{1} y_{1} \Phi\left[\delta_{1}^{2} y_{1} k_{\mathrm{h}}-\delta_{\mathrm{h}}^{2} y_{\mathrm{h}} k_{1}-\delta_{1} \delta_{\mathrm{h}} P^{\prime}\left(\delta_{1} y_{1}-\delta_{\mathrm{h}} y_{\mathrm{h}}\right)\right]}{k_{1} \pi_{y_{\mathrm{h}} y_{\mathrm{h}}}^{\mathrm{h}}} .
$$

The denominator of (25) is negative by (5) and (8). When $\delta_{1}=0, \delta_{\mathrm{h}}=0$ by condition (10) and industry profitability does not change. When $\delta_{1}>0$, a sufficient condition for the expression in square brackets to be positive is $\left(\delta_{1}^{2} y_{1} k_{\mathrm{h}}-\right.$ $\left.\delta_{\mathrm{h}}^{2} y_{\mathrm{h}} k_{1}\right)>0$ by lemma 1. Factoring this term yields $\left(\delta_{1}^{2} y_{\mathrm{l}} k_{\mathrm{h}}-\delta_{\mathrm{h}}^{2} y_{\mathrm{h}} k_{\mathrm{l}}\right)=$ $\left(\delta_{1}^{2} y_{1} c_{y_{\mathrm{h}} y_{\mathrm{h}}}^{\mathrm{h}}-\delta_{\mathrm{h}}^{2} y_{\mathrm{h}} c_{y_{1} y_{1}}^{1}\right)-\delta_{\mathrm{h}} \delta_{1} P^{\prime}\left(\delta_{1} y_{1}-\delta_{\mathrm{h}} y_{\mathrm{h}}\right)$, which is positive by $(3),(10)$ and lemma 1 . Therefore, the term in square brackets is positive and industry profitability increases iff $\Phi>0$.

The price-cost margin of firm $i$ is represented by the Lerner index, which, making use of first-order condition (4), is $L_{i}=-\delta_{i} y_{i} P^{\prime} / P$. The change in the Lerner index is $\mathrm{d} L_{i} / \mathrm{d} \theta=\delta_{i} P^{-2}\left[P^{\prime} y_{i}(\mathrm{~d} P / \mathrm{d} \theta)-P y_{i}\left(P_{\theta}^{\prime}+P^{\prime \prime}(\mathrm{d} Y / \mathrm{d} \theta)\right)-P P^{\prime}\left(\mathrm{d} y_{i} /\right.\right.$ $\mathrm{d} \theta)$ ], which yields

$$
\frac{\mathrm{d} L_{\mathrm{h}}}{\mathrm{d} \theta}=\frac{-\delta_{\mathrm{h}} y_{\mathrm{h}} \Phi\left[P c_{y_{\mathrm{h}} y_{\mathrm{h}}}^{\mathrm{h}}-\delta_{\mathrm{h}} P^{\prime}\left(P+\delta_{\mathrm{h}} y_{\mathrm{h}} P^{\prime}\right)\right]}{P^{2} P^{\prime} \pi_{y_{\mathrm{h}} y_{\mathrm{h}}}^{\mathrm{h}}}
$$

and

$$
\frac{\mathrm{d} L_{1}}{\mathrm{~d} \theta}=\frac{-\delta_{1} \Phi\left\{P y_{1} c_{y_{1} y_{1}}^{1} k_{\mathrm{h}}-\delta_{\mathrm{h}} P^{\prime}\left[y_{1} c_{y_{1} y_{1}}^{1}\left(P+\delta_{\mathrm{h}} y_{\mathrm{h}} P^{\prime}\right)-P^{\prime} \delta_{\mathrm{h}} y_{\mathrm{h}}\left(P+\delta_{1} y_{1} P^{\prime}\right)\right]\right\}}{P^{2} P^{\prime} k_{1} \pi_{y_{\mathrm{h}} y_{\mathrm{h}}}^{\mathrm{h}}} .
$$

The denominator of (26) is positive by (5), while the denominator of (27) is positive by (5) and (8). When $\delta_{i}=0$, the market power of firm $i$ does not change. 
When $\delta_{i}>0$ and $c_{y_{i} y_{i}}^{i} \geqslant 0$, market power increases in (26) and (27) iff $\Phi<0$ by (4) and (8). Q.E.D.

A demand shift has no effect on price in a free-entry competitive equilibrium. Low- and high-cost competitive firms do not adjust output in response to changes in demand conditions, while high-cost entry (resp. exit) occurs in response to upwards (resp. downwards) shifts in demand. Industry output increases by $y_{\mathrm{h}}$ in expression (15) for every high-cost firm which enters the industry through (14) in the competitive case.

In noncompetitive environments, the effect of a demand shift in a free-entry equilibrium modifies several implications which arise with a fixed number of firms. Quirmbach (1988) finds that an increase in industry output is a necessary condition for a decrease in the equilibrium price. This need not be the case in free-entry equilibria. In response to a downward parallel shift in demand, for example, the equilibrium price declines when demand is convex by proposition 3 , while high-cost firms exit the industry and aggregate output decreases by proposition 2. Quirmbach also derives the intuitive result that a decline in the equilibrium price is a necessary condition for a decrease in industry profitability. We find just the opposite in a free-entry oligopoly equilibrium. In an oligopolistic industry with free entry, a decline in the equilibrium price is both a necessary and a sufficient condition for industry profitability to increase by proposition 3 .

The change in industry concentration is positively-related to the change in profitability for an exogenous shock that rotates demand through the equilibrium point or involves a parallel shift of a non-convex demand function. This result is consistent with the positive relationship between industry concentration and profitability found by Dixit and Stern (1982) and Clarke and Davies (1982) for asymmetric-cost oligopoly equilibria with a fixed number of firms.

A rotation of demand through the equilibrium point always leads to antithetical changes in industry concentration and incumbent price-cost margins in a free-entry oligopoly equilibrium. This result is consistent with the empirical regularity of decreased market power estimates during periods of heightened industry concentration, as demand rotations correspond with the precise situation in which market power is identified in intra-industry studies [see Bresnahan (1982); Just and Chern (1980), and Lau (1982)]. The intuition for an inverse relationship between industry concentration and market power under these circumstances is as follows. Consider a market demand curve that is of less than unit elasticity. Such a market is characterized by relatively "soft" rival price-response behavior compared to the unit-elastic case, as a marginal expansion of output by an incumbent firm is associated with a larger decrease in the equilibrium price. Thus, higher price-cost margins are maintained, ceteris paribus, and a greater number of inefficient, high-cost firms produce in the equilibrium of the relatively inelastic demand market. If an exogenous shock then rotates demand counterclockwise through the equilibrium point, the demand function becomes more readily able to absorb 
increases in production without creating large, commensurate decreases in the equilibrium price. Consequently, incumbent firms expand output, industry pricecost margins decrease, and high-cost firms exit the industry, thereby increasing industry concentration. To the extent that structural differences between free-entry oligopoly equilibria result from variation in the slope of demand, one might expect market power to be lower in highly concentrated industries.

In a wide range of circumstances, changes in industry profitability are inverselyrelated to changes in market power following a demand shift. This result underscores an important issue in market regulation. If market power is an effective proxy for efficiency loss in an industry, as in Dansby and Willig (1979), incumbent firms in a free-entry oligopoly are likely to have private objectives that are well-aligned with social objectives in response to perturbations of demand. Increased market power in a free-entry equilibrium is both socially undesirable and privately disadvantageous, as large price-cost margins stimulate entry and reduce the profits of incumbent firms. It follows that changes in industry structure, per se, do not warrant market intervention, whence our analysis arrives at a familiar location in the policy debate by means of a quite different vehicle.

The present model has a variety of applications. For example, the demand-side interaction variable encompasses effects which occur through trade liberalization, environmental regulation, producer liability, and advertising. In advertising contexts, the implication of the model is that increased advertising intensity is most profitable when new customer demand is more elastic than that of existing customers. In the context of international trade, domestic profitability may increase with trade liberalization if demand shifts downward but becomes more elastic with the availability of foreign products.

The demand-side interaction variable is also useful for the analysis of tax incidence. For example, a specific tax affects the price received by firms as $P_{\theta}<0$ and $P_{\theta}^{\prime}=0$, while an ad valorem tax, which rotates the demand curve downward about its horizontal intercept, involves $P_{\theta}<0$ and $P_{\theta}^{\prime}>0$ in equilibrium. For the examination of comparative incidence, tax reforms which hold the value of $P_{\theta}$ constant are first-order revenue neutral. Thus, the model extends the result of Dierickx et al. (1988) that increases in low-cost market share are more likely with ad valorem taxes than with equal-yield unit taxes to free-entry oligopoly equilibria. While a tax of either form increases the profits of low-cost firms when demand is concave, as in Dierickx et al. (1988) and Kimmel (1992), a first-order

\footnotetext{
${ }^{8}$ The use of revenue neutral tax reforms for the analysis of comparative incidence follows Suits and Musgrave (1955). A first-order revenue neutral tax reform corresponds with the "P-shift" from specific to ad valorem taxation considered by Delipalla and Keen (1992).
} 
revenue neutral reform from specific to ad valorem taxation always increases industry profitability in (25). Moreover, such a tax reform increases industry output in (15) and lowers the equilibrium price in (24), as found by Delipalla and Keen (1992). In free-entry oligopoly equilibria, it follows that ad valorem taxes Pareto-dominate specific taxes in the sense of Skeath and Trandel (1994).

\section{Concluding comments}

The central purpose of this paper was to examine the structural implications of demand shifts in free-entry oligopoly equilibria. In response to demand shifts, a decline in the equilibrium price was shown to be a necessary and sufficient condition for incumbent output and industry profitability to increase under oligopolistic market structures. A wide range of outcomes are possible regarding changes in market share, concentration, and the equilibrium number of firms. However, when attention was focused on conditions which allow market power to be identified in intra-industry studies, changes in market power were shown to be inversely-related to both changes in concentration and in incumbent market share.

The paper made an important distinction between the motivation for de novo entry in an industry and implications of entry on market performance. If the impetus for entry is a parallel upwards shift in demand, industry output always expands as entry occurs, as in Seade (1980). Conversely, if the motivation for entry is a clockwise rotation of demand, the paper demonstrated that industry output always contracts as entry occurs.

In a wide range of circumstances, an inverse-relationship was found between changes in industry profitability and changes in the price-cost margins of incumbent firms. This result highlights an important issue in market regulation. To the extent that industry price-cost margins proxy efficiency loss in free-entry oligopoly equilibria, private and social incentives may be well-aligned in response to perturbations of demand.

An interesting area for future research is to consider collusion incentives in a somewhat richer context which includes both intra-industry and inter-industry conditions. A modification of the present model along dynamic lines may allow parameterization of collusive relationships which depend on a continuum of entry conditions. While theory might suggest the familiar collusion incentive to increase price-cost margins under conditions of perfect entry deterrence, perfect market contestability may create a quasi-competitive climate in which firms collude to reduce price-cost margins due to entry considerations. As the entry of small, inefficient firms is likely to be socially undesirable in oligopolistic industries [see Dierickx et al. (1988)], such forms of collusion may be welfare-improving in broad classes of market equilibria. 


\section{Acknowledgements}

The author acknowledges helpful conversations with Joseph Farrell, Jeffrey Perloff, Theodore Keeler, and Rickard Sandin.

\section{References}

Besley, T.J., 1989. Commodity taxation and imperfect competition: A note on the effects of entry. Journal of Public Economics 40, 359-367.

Bresnahan, T., 1982. The oligopoly solution concept is identified. Economics Letters 10, 87-92.

Clarke, R., Davies, S., 1982. Market structure and price-cost margins. Economica 49, 277-288.

Cowling, K.G., Waterson, M., 1976. Price-cost margins and market structure. Economica 43, 267-274.

Dansby, R.E., Willig, R.D., 1979. Industry performance gradient indexes. American Economic Review 69, 249-260.

Delipalla, S., Keen, M., 1992. The comparison between ad valorem and specific taxation under imperfect competition. Journal of Public Economics 49, 351-367.

Dierickx, I., Matutes, C., Neven, D., 1988. Indirect taxation and Cournot equilibrium. International Journal of Industrial Organization 6, 385-399.

Dixit, A., 1986. Comparative statics for oligopoly. International Economic Review 27, 107-122.

Dixit, A., Stern, N., 1982. Oligopoly and welfare: A unified presentation with applications to trade and development. European Economic Review 14, 123-143.

Geroski, P.A., 1995. What do we know about entry?. International Journal of Industrial Organization $13,421-440$.

Hamilton, S.F., Sandin, R., 1997. Subsidies in oligopoly markets: A welfare comparison between symmetric and asymmetric costs. Public Finance Review, forthcoming.

Harris, F., 1988. Testable competing hypotheses from structure-performance theory: Efficient structure versus market power. Journal of Industrial Economics 36, 267-280.

Joesch, J., Zick, C.D., 1994. Evidence of changing contestability in commercial airline markets during the 1980's. Journal of Consumer Affairs 28, 1-24.

Just, R.E., Chern, W.S., 1980. Tomatoes, technology, and oligopsony. Bell Journal of Economics 11, 584-602.

Kimmel, S., 1992. Effects of cost changes on oligopolists' profits. Journal of Industrial Economics 40, 441-449.

Koontz, S., Garcia, P., Hudson, M., 1993. Meatpacker conduct in fed cattle pricing: An investigation of oligopsony power. American Journal of Agricultural Economics 75, 537-548.

Lau, L., 1982. On identifying the degree of competitiveness from industry price and output data. Economics Letters 10, 93-99.

Mankiw, G., Whinston, M., 1986. Free entry and social efficiency. Rand Journal of Economics 17, $48-58$.

Murray, B.C., 1995. Measuring oligopsony power with shadow prices: U.S. markets for pulpwood and sawlogs. Review of Economics and Statistics 77, 486-498.

Nebesky, W., McMullen, B.S., Lee, M., 1995. Testing for market power in the U.S. motor carrier industry. Review of Industrial Organization 10, 559-576.

Pagoulatos, E., Sorenson, R., 1986. What determines the elasticity of industry demand?. International Journal of Industrial Organization 4, 237-250.

Quirmbach, H., 1988. Comparative statics for oligopoly: Demand shift effects. International Economic Review 29, 451-459.

Reinganum, J., 1985. Innovation and industry evolution. Quarterly Journal of Economics 100, 81-99. 
Schroeter, J., 1988. Estimating the degree of market power in the beef packing industry. Review of Economics and Statistics 70, 158-162.

Seade, J., 1980. On the effects of entry. Econometrica 48, 479-489.

Seade, J., 1987. Profitable cost increases and the shifting of taxation. University of Warwick Economic Research Paper \# 260.

Skeath, S.E., Trandel, G.A., 1994. A Pareto comparison of ad valorem and unit taxes in noncompetitive environments. Journal of Public Economics 53, 53-71.

Suits, D.B., Musgrave, R.A., 1955. Ad valorem and unit taxes compared. Quarterly Journal of Economics 67, 598-604.

Vickers, J., 1986. The evolution of market structure when there is a sequence of innovations. Journal of Industrial Economics 35, 1-12.

Vickers, J., 1989. The nature of costs and the number of firms at Cournot equilibrium. International Journal of Industrial Organization 7, 503-509. 